\title{
LA NACIÓN SEGÚN FUENTES: LA MUERTE DE ARTEMIO CRUZ Y LA NUEVA LEGALIDAD DE LA NOVELA TOTAL
}

The nation according to Fuentes: La muerte de Artemio Cruz and the new legality of the totalizing novel

\section{IGNACIO RUIZ-PÉREZ University of Texas at Arlington (USA) iruiz@uta.edu}

Ya desde desde Los días enmascarados (1954), su primer libro de cuentos, Carlos Fuentes (1928-2012) adelantaba la que sería una de sus obsesiones más duraderas y definitivas: la indagación sistemática de México en cuanto complejo cultural, social e histórico. Del entramado de esos tres niveles, el escritor mexicano extrae una política de los fundamentos de la nación que nutrirá buena parte de su obra por lo menos hasta Adán en Edén (2009). Uno de los más grandes descubrimientos del escritor en su volumen de cuentos inaugural será la memoria como tema para repensar los fundamentos ideológicos en los que se levanta la nación. De hecho, al menos dos de los relatos de Los días enmascarados ("Chac Mool" y "Tlactocatzine del jardín de Flandes") se desarrollan alrededor de la presencia ritual y perturbadora de un pasado indígena incorporado solo de manera superficial al discurso desarrollista y ecuménico de los años 50 en México.

La memoria de esas "viejas formas de vida", como las llamó Fuentes en una entrevista posterior con Emanuel Carballo (1986, p. 535), será precisamente la materia narrativa en la que se levantará, en un doble movimiento estético y vital, el proyecto literario del escritor mexicano. Narrar para Fuentes tendrá una función axiológica en dos sentidos: por un lado fundamenta los cuestionamientos personales y vivenciales de un autor que tuvo que inventar su propio idioma e imagen del país debido a la actividad diplomática de su padre; y por otro sintetiza de manera paradigmática las exploraciones en torno a la identidad del mexicano que entre 1920 y 1930 realizaron José Vasconcelos y Samuel Ramos, y que revitalizaron Octavio Paz y el grupo Hiperión (Emilio Uranga, Luis Villoro, Leopoldo Zea, entre otros) en plena década de los 50. De esta forma, la memoria en la obra de Fuentes cumplirá una función de síntesis de las partes constitutivas de la nación en cuanto complejo cultural, histórico y social, que rompe con la tradicional formación discursiva de un país bifronte, formado a partir de sedimentos étnicos oposicionales únicos y definidos. Esa operación ideológica sirve a Fuentes para oponer una totalidad dialéctica que abarca el todo y las contradicciones inherentes en su formación, como mencionará el escritor mexicano en ese elogio de la novela total pero también de la imaginación híbrida que es Cervantes o la crítica de la lectura (1976). Narrar, de esta manera, se convierte en una relativización de los absolutos, y ese cuestionamiento de paradigmas estáticos pasa por una operación crítica que sintetiza 
todos los presupuestos que componen esa totalidad creando una obra híbrida (o, visto de otro modo, un paradigma estético) que no es más que el procedimiento mismo de síntesis que realiza la memoria en su búsqueda de unidad. El texto modélico de la relativización de los absolutos y de la puesta en marcha de la ambigüedad novelesca como base de la modernidad es El Quijote. A partir de esta obra, a la que Fuentes volverá repetidamente para esbozar su muy personal geografía de la novela, el escritor funda su propia genealogía y la de sus pares en el mundo de habla hispana.

En esa negociación dialógica de las partes tendrá un papel primordial la memoria como base de la articulación ficcional de una narrativa de sesgo histórico en la que volver a contar la historia significa completar las elipsis y los paréntesis que esta contiene: reflexionar pertinente a México es contar la nación, imaginarla, ir a contrapelo de las narrativas oficiales y de sus mecanismos opresivos a partir de la subversión de un lenguaje otorgado (el español, en este caso) en cuya sintaxis y significados permanecen aún los signos de la Colonia. Más aún, narrar es un procedimiento crítico y deconstructivo que empieza por descolonizar el lenguaje, procedimiento que consiste, en un segundo grado, en apropiarse de él y descomponerlo hasta su gramática esencial con base en recursos de una radicalidad similar a la emprendida desde la poesía por el modernismo hispanoamericano y se consolida después por las vanguardias. La desacralización del lenguaje compone un linaje literario crítico (de Borges a Rulfo, y de Carpentier a Cortázar) que Carlos Fuentes habrá de reconocer sin ambages en La nueva novela hispanoamericana (1969), y en el que el autor mexicano habrá de ubicar su propia obra.

Desde el inicio de su carrera como escritor, Fuentes (1972) descubrió en la articulación de un lenguaje narrativo la vía de acceso a la libertad imaginativa. De ahí que no sorprenda que uno de sus apotegmas más reconocibles en torno a la nueva novela hispanoamericana sea aquel donde señala que esta es mito, lenguaje y estructura (p. 20). Según Fuentes, el novelista hispanoamericano parte de esa trinidad creativa para proporcionar voz a lo que no la tiene, o para denunciar los silencios de la historia oficial pero no con base en la descripción mimética de la realidad, sino en la revelación de su esencial heterogeneidad, en su apertura crítica y creativa. Se trata, en otras palabras, de destruir el mundo para volver a fundarlo y hacerlo inteligible a partir del lenguaje. En ese sentido, el narrador mexicano se adscribe a lo que Vargas Llosa reconoció en Carta de batalla por Tirant lo Blanc como una "estirpe de suplantadores de Dios -Fielding, Balzac, Dickens, Flaubert, Tolstoi, Joyce, Faulkner- que pretenden crear en sus novelas una 'realidad total', el más remoto caso de novelista todopoderoso, desinteresado, omnisciente y ubicuo" (p. 11). Dicho de otro modo, el autor de novelas totalizantes exige al lector no solo su empatía sino además su implicación racional en los distintos niveles narrativos, simbólicos e ideológicos del texto. La obra abierta que se completa de manera dialógica es una de las modalidades de una literatura que se asume múltiple, heterogénea y ambigua, pero también compleja y absoluta, tanto como la misma 
realidad de la que parte. El novelista es, en definitiva, un deicida porque su obra suplanta la realidad.

Ahora bien, en el proyecto narrativo de Fuentes, La región más transparente (1958) es el primer paso en la integración de una praxis de la novela total que se consolidará tan solo cuatro años más tarde en La muerte de Artemio Cruz. Las dos novelas tienen en el fondo el mismo fundamento: revisar las narrativas oficiales en los que se levanta la formación discursiva del país a partir de la imaginación de la historia. La muerte de Artemio Cruz es la reflexión, el discurrir de la conciencia (discurso, materia novelable y rememorada) y el acto confesional de un sujeto que es el prototipo de las mitologías y símbolos que subyacen en el subconsciente colectivo de todos los mexicanos.

La función del novelista es describir la realidad heterogénea compuesta de diferentes sedimentos, ya sean estos culturales, sociales o históricos, y darles un sentido narrativo, una coherencia diacrónica que revele sus orígenes pero también sus aperturas. En ese sentido, la novela busca recuperar la relación especular entre la historia privada de Artemio Cruz y la historia colectiva del país, lo que convierte al personaje en un signo de los distintos discursos ideológicos que cimientan la formación discursiva de la identidad nacional. Para reflexionar acerca de Artemio Cruz en cuanto circunstancia y héroe problemático, Fuentes acude a la dilucidación del origen del personaje a partir de la experiencia de su muerte. El deseo de Artemio Cruz por recuperar su pasado es inversamente proporcional al del lector por conocer la identidad del personaje, que está íntimamente ligada a la historia del país. Visto de esa forma, el viaje a la semilla que plantea la novela de Fuentes (ya explorado en términos parecidos por Alejo Carpentier en su cuento de 1944) es, de manera simultánea, una reflexión viva respecto del conjunto de circunstancias históricas que abarca el país a partir de las distintas mitologías que integran el imaginario de los mexicanos. Aquí Fuentes sigue de cerca $E l$ laberinto de la soledad de Octavio Paz, cuyo concepto de "soledad histórica" se puede rastrear en el pensamiento perteneciente a lo mexicano durante el periodo en que el escritor publica su novela, y que aborda el asunto no desde un ángulo esencialista sino mitohistórico. Es decir, al igual que Octavio Paz en El laberinto de la soledad, el novelista propone una viva reflexión de México no desde la particularidad esencialista de sus creencias e imágenes (mitos), sino a partir de lo que estas dicen de las circunstancias históricas del país, y de lo que esas mismas circunstancias tienen en cuanto tentativa de inserción en el ámbito universal.

De acuerdo con Paz, el mexicano se caracteriza por su orfandad y soledad, como le sucede a cualquier sujeto sin distinción de origen. El hecho de nacer es ya un desprendimiento de la continuidad con la madre (una ruptura); el individuo es, en fin, un "ser para la muerte", advierte Heidegger, cuya obra Fuentes conocía bien gracias al magisterio directo del filósofo español José Gaos exiliado en México ${ }^{1}$. Escindido,

${ }^{1}$ En "España y México, México en España", Fuentes menciona explícitamente la impronta del exilio español (José Gaos, Luis Cernuda, Emilio Prados, Eduardo Nicol, Manuel Pedroso y Luis 
el sujeto se reconoce Otro, solo y separado de sí mismo. Ahora bien, según Octavio Paz la vía para recuperar la felicidad perdida es la vuelta al origen, ya sea mítico o histórico, pero en cualquier caso redentor. Carlos Fuentes, por su parte, propone una reinvención de la historia de México a partir de la creación de un nuevo mito de origen que haga legible la historia; una narrativa que, en otras palabras, refunde legalmente (del latín lex) la legibilidad de la nación para conseguir, con ello, la redención y la consecuente inserción del país en el curso de la historia universal. Artemio Cruz se convierte en un símbolo del sacrificio crístico, y el reconocimiento de su origen bastardo coincide con la redención y la libertad a las que alude el escritor al citar a Montaigne al principio de la novela (La préméditation de la mort es préméditation de liberté). Redimirse es también reconciliarse consigo mismo: por un prodigio de la memoria, la muerte del protagonista coincide con su nacimiento, y ese símbolo de individuación ("No vale la vida: la vida no vale nada", añade otro epígrafe de la novela) se transustancia en el encuentro de la unidad perdida (la infancia, el origen) y la reparación de la ruptura original, esa etapa preverbal, anterior al lenguaje y a la historia, a la que el escritor volverá en Terra Nostra.

Al trazar el arco involutivo hacia el origen de Artemio Cruz en una suerte de desestructuración narrativa que explica bien el caos aparente y la fragmentación de la trama, Fuentes busca, por un lado, dilucidar el origen individual del protagonista de la novela. Pero, por otra parte, intenta hacer legible a un nivel colectivo el origen de las narrativas de fundación de México y la mexicanidad a partir de la articulación de una imagen mitopoética de la historia. Leer las narrativas de fundación sean estas míticas o históricas, oficiales o marginales, significa volver a establecer un marco legal, un nuevo código de lectura de la historia y de los supuestos sociales con el fin de reconocer una forma ideológica diferente a las que el país ha buscado en el transcurso de su historia -liberalismo, positivismo, socialismo, desarrollo estabilizador y, más recientemente, neoliberalismo-. Pues, como dice Enrico Mario Santí en su prólogo a El laberinto de la soledad, la relación entre los mitos y la historia es dialéctica, por eso "la descripción del mito (mythos, 'intuición') va a la par de la interpretación de la historia (logos, 'razón')" (Paz, 2015, p. 14).

De esta forma, parte de la estrategia discursiva de Fuentes en esta novela es la desestructuración del relato (o des-fundación, como advierte Julio Ortega) pero también, añado por mi cuenta, la re-fundación de la nación mediante un pacto en el que la memoria histórica y la personal (la literatura) desempeñan un papel no excluyente sino suplementario -en el sentido que da Derrida al término-. La imaginación novelística es equivalente a la imaginación historiográfica porque ambas se fundan en un acuerdo

Buñuel) en su formación intelectual. Acerca de José Gaos dice que sus lecciones le "enseñaron que la creatividad consiste en convocar un universo, más que reflejarlo ancilarmente. Basada en la realidad -la tierra, la raíz- la obra de arte crea un mundo que antes no existía: nace de la historia pero crea la historia, empezando por la historia de la propia obra de arte" (p. 245). 
verbal: nombrar es ordenar (logos), y esa estructuración del archivo equivale a seleccionar y sistematizar la materia histórica de la misma forma que el novelista procede con la materia literaria. Por eso no extraña que una de las secuencias de la novela aluda al acto de legar como un virtual acto de leer (del latín legere) y de fundamentar la ley. No es solo la herencia, sino lo que viene detrás del legado: el origen, los cimientos de esa hacienda o herencia, que no puede ser otra más que el complejo político y social sobre el que se levanta el México del moribundo Artemio Cruz. Cito por extenso:

legarás este país; legarás tu periódico, los codazos y la adulación, la conciencia adormecida por los discursos falsos de hombres mediocres; legarás las hipotecas, legarás una clase descastada, un poder sin grandeza, una estulticia consagrada, una ambición enana, un compromiso bufón, una retórica podrida, una cobardía institucional, un egoísmo ramplón; [...] tengan su México: tengan tu herencia (p. 368).

Herencia equivale a cimientos, a origen, de ahí que el narrador en segunda persona trace una espiral en esta misma secuencia y mencione el espacio original, esto es, la hacienda en la que nació el protagonista y de la que escapará después de matar a su tío, Pedro Menchaca, para partir a Veracruz, recibir su educación ideológica básica y emprender el camino hacia el centro del país, donde iniciará su ascenso fulgurante como miembro de la Revolución. Pero lo sintomático es que el punto de partida del protagonista sea Veracruz, entidad donde se fundó la Villa Rica de la Veracruz, primer ayuntamiento y ciudad del continente americano, y en cuya costa Cortés hunde sus naves en 1519 para iniciar la Conquista de México (según consta en la Segunda carta de relación del conquistador extremeño) ${ }^{2}$. Es importante resaltar que esa entidad se caracteriza por su mestizaje cultural y su fuerte impronta africana, dato incorporado de manera sustancial a la trama de la novela.

Así, Veracruz es el cronotopo en el que se entrecruzan los tiempos y espacios que forman la identidad del protagonista. Años después, un ya maduro Artemio volverá a la costa veracruzana y recuperará "Cocuya", la hacienda en la que había sido engendrado fuera de la ley, cuando su padre, el terrateniente Atanasio Menchaca, viola a su madre, la mulata Isabel. Es decir, Veracruz es el origen del discurso mítico-poético

\footnotetext{
${ }^{2}$ La crítica no ha dejado pasar este detalle aun cuando Fuentes ha mencionado en una entrevista con María Victoria Reyzábal que se trata de un hecho completamente fortuito: "[El crítico Steven Boldy] llama la atención sobre la similitud fonética Hernán Cortés-Artemio Cruz. Las carreras de ambos comienzan en Veracruz. Barrenan las naves de su pasado. Violan a Marina-Regina. Someten a Bernal-Moctezuma. Y se casan con Catalinas. Le juro que a mí nunca se me ocurrió esto" (97). No obstante, en su edición de la novela González Boixo señala que las coincidencias biográficas entre Cruz y Cortés son suficientes como para facilitar la comparación: "el inicio en Veracruz, la llegada de Cruz a Puebla desde Cholula, con referencias a las iglesias coloniales, su primer gran triunfo, como el de Cortés en Cholula (con la simbología tan acentuada que la matanza tuvo), su llegada a México y, sobre todo, que fije su residencia en Coyoacán, el barrio colonial de México, donde Cortés estableció su primera residencia” (p. 91).
} 
al mismo tiempo que este incrementa el significado del discurso historiográfico en torno al origen de México (Veracruz como espacio desde donde Cruz, como Cortés, emprende la Conquista de México) en una suerte de acto de refundación mitohistórica de la ley (logos), refundación que solo puede partir del acto de desestructurar el relato.

Esa desestructuración de la trama le sirve a Fuentes, entonces, para resaltar el "movimiento inmóvil" de la historia del país, que cambia a personajes y circunstancias por otros sujetos y sucesos, pero no para crear una verdadera transformación progresiva (evolutiva), sino una mera continuidad caracterizada por su estatismo. Artemio Cruz se convierte en imago de los históricos mecanismos de opresión del país: hijo bastardo de un conservador terrateniente criollo venido a menos, su etnicidad afromexicana es uno de los motivos que sirven a Fuentes para reflexionar en torno a la pertinencia de la conformación de la identidad nacional a partir de la dicotomía Europa-América que fomentó el discurso mestizófilo de fines del siglo XIX y de principios del XX. Artemio Cruz rompe con esa dicotomía y recupera para la memoria colectiva la raíz africana, enmascarada y oculta por la retórica nacionalista de los gobiernos en turno e impulsada con denuedo desde las artes mediante de la escuela mexicana de pintura y su efectiva pero maniquea retórica indigenista y campesina. Pues si bien el padre de Cruz es en un nivel de lectura mitopoético el Gran Chingón y un trasunto del Padre de la tradición judeocristiana de la misma manera que Cruz es el Hijo huérfano y sacrificado en la encrucijada del imaginario colectivo, en un nivel metahistórico Cruz es la suma de las tres rupturas históricas más significativas de México - Conquista, Independencia y Revolución-y de su búsqueda de inserción en la historia. En el transcurso de la novela, el protagonista rompe con su origen (el hecho de ser hijo de una violación similar a la que significó la del conquistador para la población mestiza), pelea en la Revolución y llega a ser un miembro prototípico de la "familia revolucionaria": primero se convierte en hacendado y luego en acaparador de tierras y en promotor de la reforma agraria; posteriormente extermina a los hacendados que quedan del antiguo orden porfirista, obtiene una diputación federal, compra un periódico y actúa como prestanombres de empresarios extranjeros.

En contrapunto, la novela expone los signos de descomposición del Estado nacional y anuncia una crítica profunda: las huelgas de maestros y ferrocarrileros de los 50 preludian el movimiento estudiantil del 68 y la crisis del sistema político, mientras realiza diversas alusiones al inminente triunfo de la Revolución cubana. La cronología de esos mismos acontecimientos históricos, sin embargo, aparecen en espiral formando un corsi e recorsi -diría Giambattista Vico, a quien Fuentes volverá para hablar respecto del tiempo en esa monumental teoría de la novela que es Valiente mundo nuevo (1990-que advierte que la noción diacrónica y lineal del tiempo es una invención occidental, y que el tiempo mexicano es heterogéneo e inacabado, y se caracteriza en cambio por sus repeticiones cíclicas y por sus rupturas sistémicas, rasgos compartidos, por otra parte, por esa modernidad periférica llamada Hispanoamérica. 
Por ese motivo no deja de llamar la atención que La muerte de Artemio Cruz anuncie la profunda subversión formal que Carlos Fuentes desarrollará en novelas como Cambio de piel (1967) y Terra Nostra (1975). En La muerte de Artemio Cruz la principal estrategia narrativa a la que acude el novelista es la alternancia de tres voces (yo, tú, él) que se corresponden con los distintos tiempos narrativos (pasado, presente y futuro) empleados en el texto, los que a su vez se pueden relacionar con los tres acontecimientos señeros de la historia del país y con los doce días significativos en los que Cruz ha tenido que tomar una decisión determinante para su historia personal. Así, los distintos niveles de significación proponen el paso de lo microhistórico (la novela) a lo macrohistórico (la historia nacional), prefigurando un movimiento ritual, cíclico y significativo de diversas marcas o rupturas históricas -no por nada Fuentes incluyó a la novela de marras en su ciclo narrativo "La edad del tiempo"- señeras para el país. Los restos de las antiguas formas de vida en el país son los diversos y heterogéneos tiempos históricos que se sedimentan y sintetizan en Artemio Cruz, pero que forman en cambio una conciencia híbrida que imagina la historia, la sociedad y la cultura de México a la vez que se imagina. Recuperar la alianza perdida y volver al inicio desde la muerte equivale a un renacimiento, una suerte de autognosis que tiene que ver con la identidad y con el hecho nada menor de fundar una "nueva legalidad" basada en la imaginación de un narrador trino (Artemio Cruz) que crea tres máscaras o personas -y no es gratuito que, de acuerdo con la $R A E$, esta última palabra provenga del latín persōna mediante el


actor" (Diccionario en línea)- para narrar o purgar su personal mito fatalmente enlazado a la historia del país, debido a que lo privado solo tiene sentido en función de lo colectivo, y viceversa ${ }^{3}$.

En otro sentido, la refundación de una "nueva legalidad" implica un "nuevo código de lectura" para leer ese mismo espacio, y esa lectura solo puede darse de

\footnotetext{
${ }^{3}$ Que las tres personas (yo, tú, él) en las que se encuentra estructurada la novela pueden ser una invención de Artemio Cruz es una hipótesis que aparece reforzada en los apartados en primera persona (monólogo interior), que son los que refieren la fragmentación de la subjetividad del protagonista en agonía. Lo anterior se confirma de manera concluyente en la última secuencia: "Yo no sé... no sé... si él soy yo... si tú fue él... si yo soy los tres [...] los tres... moriremos... Tú mueres... has muerto... moriré" (pp. 404-405). Este detalle trae como consecuencia un hecho nada menor: si los tres narradores son invenciones de Cruz, entonces es posible de que no sean fidedignos y que algunos de los sucesos y recuerdos sean inventados o creados por la imaginación del protagonista, como se puede leer en diversas partes del relato ("la memoria es el deseo satisfecho", p. 167; “tú inventarás y medirás un tiempo que no existe”, p. 303; “ah, soñé, imaginé, supe esos nombres", p. 337; ), y por tanto sean relativos o estén en duda. En realidad, la relativización de los hechos forma parte del programa narrativo de esta novela en particular (la imaginación como camino a la redención) y del proyecto narrativo de Carlos Fuentes en general (la ambigüedad de la novela moderna). En el centro del género estaría El Quijote, obra magna de Cervantes (crítica de la lectura) y uno de los paradigmas esenciales de la modernidad junto con el Ulysess de Joyce (crítica de la escritura).
}

AlPHA No 48 (2019) PÁGS. 237-245. ISSN 0716-4254 | 243 
manera crítica, esto es, dinámica, dialéctica, colectiva. Se trata de reescribir y refundar un cronotopo mexicano que valga no solo para leer ese mismo discurso, sino también para escribirlo o, mejor dicho, para imaginarlo de manera crítica como el propio Fuentes advierte a propósito de las escrituras de Cervantes y Joyce. "Melés, Telés y Noslés", dice el novelista en Cervantes o la crítica de la lectura, y de un único acto (leer) surge un triple pronombre que demuestra la vocación colectiva de la literatura (imaginar es crear), y su condición transgresora, ya que disloca la norma "avara del trueque entre escritor y lector, la norma colombiana del melés y teleo" $(1976,109)$. La literatura es, como las palabras, una creación colectiva porque refiere directamente a la "experiencia del ser del lenguaje" (cursivas en el original; 1976, 110).

Vista a la luz de esa teoría crítica de la lectoescritura que propone Fuentes, la muerte del personaje central cumpliría la función de vía de catarsis colectiva dentro del esquema narrativo en un doble círculo concéntrico que va de la literatura a la historia, y viceversa: la vida de Cruz se inicia en el lejano 1889, en pleno porfiriato que ya preludia sin embargo el movimiento de 1910 debido a las condiciones sociales de las que el propio Cruz es víctima como afromexicano en el sistema de haciendas del siglo XIX; por el contrario, la muerte del personaje en 1959 coincide con la idea de la generación de Fuentes -la de Medio siglo- respecto del agotamiento y la muerte de la Revolución mexicana (Krauze, 1981, p. 35) gracias a la corrupción de sus caudillos convertidos en políticos u hombres de negocios, como el propio Cruz. Más aún, 1959 es el año del triunfo de la Revolución cubana, que muchos intelectuales mexicanos e hispanoamericanos en general interpretaron como un renacimiento de la utopía.

La marca directa de época se puede apreciar en los años y espacios de escritura que de manera estratégica coloca Fuentes al final de su novela: "La Habana, mayo de 1960. / México, diciembre de 1961" $(2008,405)$. La desestructuración del relato se corresponde con la corrupción del cuerpo ya corrompido políticamente de Artemio Cruz (y de México) y con la desintegración de su conciencia, lo que anuncia la re-fundación mítico-poética del país por medio de los diversos movimientos sociales de los 60 que demandaban la apertura democrática, al tiempo que referían a la utopía de la "nueva legalidad" hispanoamericana. Con semejante clausura narrativa, el novelista pasaba del ámbito mexicano a uno más amplio y de mayor alcance geopolítico, de lo individual a lo colectivo, y de lo nacional a lo global. Es decir, en cuanto obra colindante con la metaficción historiográfica, La muerte de Artemio Cruz representa "lo real como falso para que el discurso sea fábula crítica, y para que la novela sea el nuevo texto de la política" (Ortega, 2002, p. 203). La "infidencia narrativa" de Artemio Cruz-para emplear el término acuñado por Juan Bautista Avalle Arce a propósito de El Quijote (167)- tiene por objetivo escamotear la información, retardar su aparición o simplemente inventarla, con lo que, muy cervantinamente, Fuentes cuestiona el edificio de la verosimilitud narrativa para poner en duda los supuestos históricos e ideológicos inamovibles y articular en cambio una política y crítica de la novela total; en suma, una conciencia de la imaginación como fundamento de la libertad. 


\section{OBRAS CITADAS}

Avalle Arce, Juan Bautista (1987). "Cervantes y el narrador infidente". Dicenda: Cuadernos de Filología Hispánica 7: 163-172.

Carballo, Emanuel (1986). Protagonistas de la literatura mexicana. México: SEP/Ediciones del Ermitaño.

Fuentes, Carlos (1972). La nueva novela hispanoamericana. México: Joaquín Mortiz.

— (1976). Cervantes o la crítica de la lectura. México: Joaquín Mortiz, 1976.

(1995). "España y México, España en México". Inti 42: 243-249

(2008). La muerte de Artemio Cruz. Ed. José Carlos González Boixo. Madrid: Cátedra.

Krauze, Enrique (1981). "Cuatro estaciones de la cultura mexicana". Vuelta 60: 27-42.

Ortega, Julio (2002). "La muerte de Artemio Cruz y el relato de la des-fundación nacional". Hispania 85.2: 198-208.

Paz, Octavio (2015). El laberinto de la soledad. Postdata. Vuelta a El laberinto de la soledad. Ed. Enrico Mario Santí. México: Fondo de Cultura Económica.

Reyzábal, María Victoria (1988). "Mantener el lenguaje o sucumbir al silencio. (Entrevista a Carlos Fuentes)". Carlos Fuentes: premio de literatura en lengua castellana "Miguel de Cervantes" 1987. Madrid: Anthropos / Ministerio de Cultura, 83-102.

Vargas Llosa, Mario (1991). Carta de batalla por Tirant lo Blanc. México: Seix Barral. 